\title{
Public Road Transport Guiding System using Arduino Microcontroller
}

\author{
K. Vidyasagar \\ Dept. of ECE, SSIT,Sathupally,
}

T.S, India

\author{
Md. Abdul Farooq \\ Dept. of ECE, SSIT,Sathupally, \\ T.S, India
}

\author{
K. Suresh \\ Dept. of ECE, SSIT,Sathupally, \\ T.S, India
}

\begin{abstract}
Majority of the public transport supportive system is not user friendly. An ambiguity on the available state of the transport bus may lead to poor performance of the supportive mechanism. . The advancement of technology enabled, to meet the requirements of the supportive mechanism. The bus is entering into the bus stand premises, the bus is located at the stop point, the bus is leaving out gate, next bus in a queue, such information will be displaced at the appropriate display point and an automatic announcement is added to the proposed work. 'ARDUINO' Micro controller is adopted to regulate the process. Three IR Sensors are inputted to Arduino controller. An RFID reader at the entrance gate of the bus stand will detect the entry level of the bus, and the gate controlling mechanism will verify the authorization of the bus to enter into the bus stand premises.
\end{abstract}

\section{Keywords}

ARDUINO Micro controller, RFID Reader

\section{INTRODUCTION}

Road transport system will be powered by adopting the growing technology to make sense for the society. Monitoring the state of each platform manually may leads to inappropriate errors. Tracking of the bus on the platform manually is a tedious process. Supervise the process and display the state of each platform

can

be accomplished by means of Ardino microcontroller supported by the RFID and infrared Technology. Unauthorized vehicles will be restricted in the bus stand premises using the proposed RFID Technology. The proposed methodology was developed for implementatio $\mathrm{n}$ in real time application.

\section{LITERATURE SURVEY}

Mrs.Swati Chandurkar, Sneha Mugade, Sanjana Sinha, Megharani Misal, Pooja Borekar focused to install Global positioning system (GPS) on City buses to implement the real time passenger information system. The bus tracking at the control room is developed to meet the challenges of web based interface at the central control room, expected time of arrival at bus stops, mobile application to know the bus schedule [1].

Menon1, R. Sinha, D. Ediga, Prof. Subba Iyer proposed the implication of internet of things in bus transport system of Singapore. This paper also compared the developed application with the existing applications [2].

Aparna A. Surve, Rutuja P. Nahar, Gauri K. Somavanshi, Kranti Dive, proposed a methodology to Enhancing the Functionality of Bus Monitoring and Tracking System. The author focused to reduce the waiting time of the passengers by implementing the GPS system. the exact time and location of the bus is estimated with the proposed methodology. I2 T algorithm is applied to determine the shortest path between the user and the nearest bus stop [3].

Sunil Praneel Narayan, Mansour H. Assaf, Shalvindra Krishneel Prasad, proposed automated vehicle identification system . Public vehicle location. System (PVLS) is proposed with the support of RFID readers and tags. Managing the RFID readers at various locations is the major contribution of the proposed work [4].

Gunjal Sunil N. , Joshi Ajinkya V. , Gosavi Swapnil C. , K.shirsagar, V.yanktesh B proposed a methodology using Global position system to estimate the expected time of arrival at the located places using internet [5].

Karan Punjabi, Pooja Bolaj, Pratibha Mantur, Sneha Wali proposed a methodology using GPS and Global position receiving system (GPRS) to implement the college bus locator using Via SMS using android application. Location based service is the focused aim of this work [6].

Swapnil Bhosale, Abhishek Aru, Tushar Jashav, Vikas Kalokhe, Santosh Sambare proposed a methodology to implement RFID based bus tracking system. The author focused on GSM modem and RFID reader. At 89 S 52 is used as superstation controller [7].

Komal Agarwal, Kimaya Dhaigude, Priyanka Kataria, Dipti Parakh proposed a methodology for Public Transportation Management System. The work focused on a black box equipped in a bus contains RFID reader and GSM. The communicated information between RFID reader and RFID tag will be sent to the base station using GSM Technology [8].

RohanKale proposed a methodology to implement Real Time Passenger Information System. This work focused to1. display the arrival time of the buses at all the bus stop locations, 2. Control room monitoring by adopting the web based control, 3. Expected time to reach the destination.[9].

\section{HARDWARE COMPONENT DESCRIPTION}

\subsection{RFID Reader}

EM 18 RFID Reader is equipped at the entrance gate of the bus stand. Each bus is housed with the RF ID identity tag. The information to be identified is stored in the microchip for transmission to the RFID reader using an antenna. The reader will communicate to the Arduino Microcontroller serially using the MAX 232 line driver to verify the threshold value. Fig 3.1 represents EM18 used as a RFID reader. 


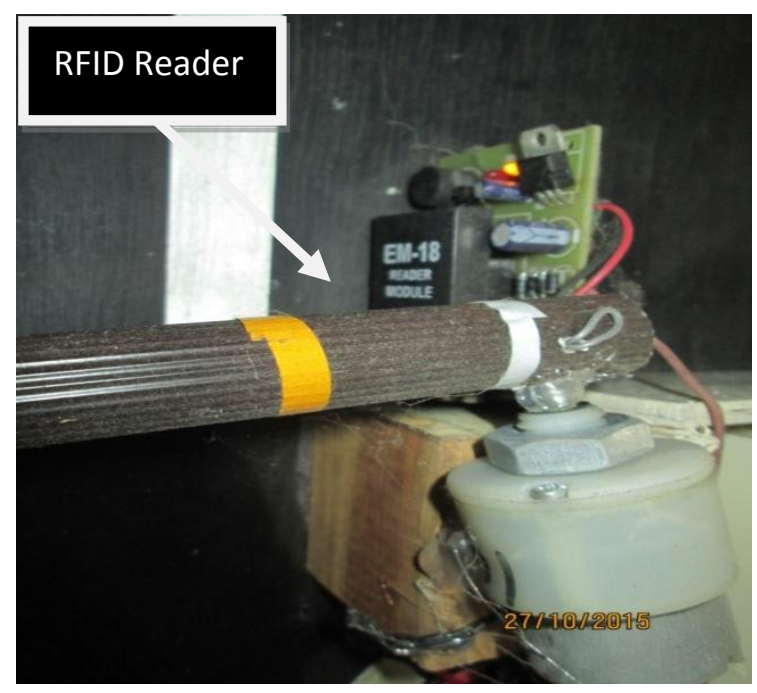

Fig.1 RFID Reader

\subsection{IR sensor}

An IR Sensor equipped at the exact location of the parking place to detect the bus. If the detection is true then the IR sensor will fed $5 \mathrm{~V}$ signal to the Arduino microcontroller. A beep signal enables to transmit the command signal to the control room cause to display the present state of the bus.

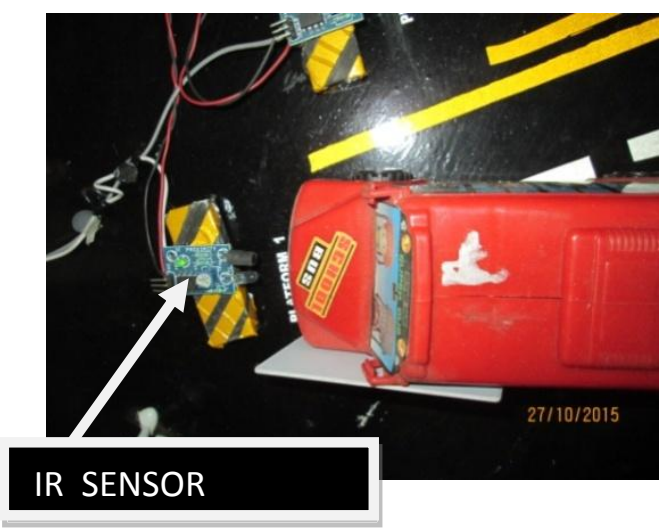

Fig.2 IR sensor detected when bus at platform

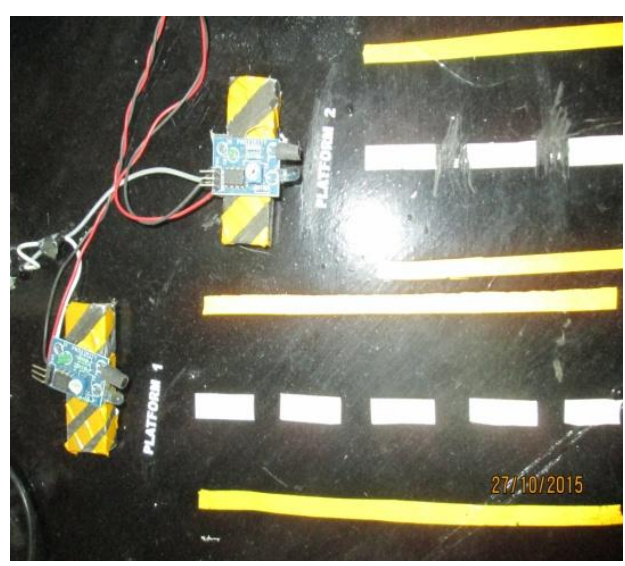

Fig.3 Two IR sensors at two platforms

\subsection{Audio play back Board}

APB 33A3 Audio play back board is used to address the public passengers. APB 33A3 housed with Eight Channels (M0 -M7). Each channel can hold the audio information maximum of 1.3 minutes. The total playback voice is ' 11 ' minutes only. Jumper 5 (J5) used to select the channels. Keeping the jumper (J1) in record mode connect to the ground and on chip MIC used for recording the voice. The status LED 1 will be on for 1.3 minutes and it turns off after the duration is full. The public addressing speaker is connected to the jumper 4 (J4).

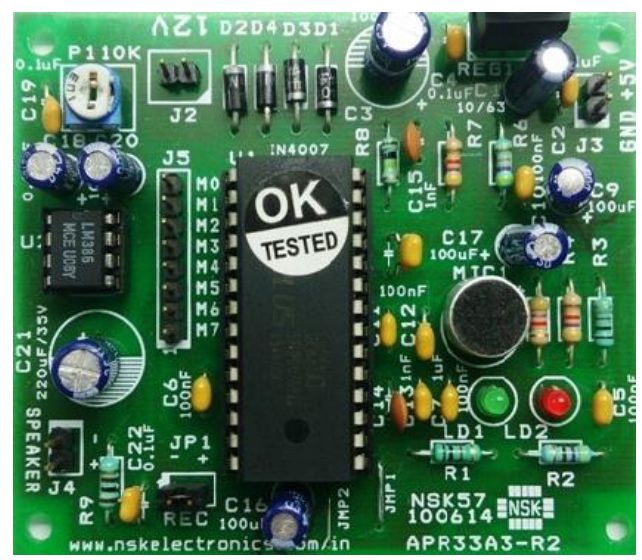

Fig.4 Audio play back circuit board

\section{METHODOLOGY}

Initialize an address for Vijayawada rout bus

Initialize an address for Khammam rout bus

Initialize an address for Kothagudem rout bus

Initialize the audio play back (APB) module for public addressing

Initialize the Loop1 iteration count

Initialize the Loop 2 iteration count

Initialize the loop 3 iteration count

Initialize the LCD display

Initialize the Gate driving motors

\section{LOOP 1}

Read the RFID reader

If

The pin goes high

Then decode the address

If

The address is for Vijayawada

Then display the message "Vijayawada bus is at the in gate"

Enable the APB module

Else if

The address is for Khammam

Then Display the message "Khammam Bus is at the in gate

Enable the APB module

Else if

The Address is for kothagudem

Then Display the message "Kothagudem bus is at the in gate"

Enable the APB module 
Else

Display the message "Bus is not available "

Enable the APB module

Decrement the loop 1 iteration count by 1

Open the in gate

Go to loop 2

\section{LOOP 2}

Read the IR Sensor 1

If the output line is high

Then Display the message "Vijayawada bus is at platform"

Enable the APB module

Else if

Read the IR sensor 2

If the output line is high

Then display "Khammam bus is at platform"

Enable the APB module

Else if

Read the IR sensor 3

If the Output line is high

Then display "Kothagudem bus is at plat form"

Enable the APB module

Else

Display "welcome to Sattupalli"

Decrement the loop 2 Iteration count by 1

Go to loop 3

\section{LOOP 3}

Read the RFID reader at the Out gate

If

The pin goes high

Then decode the address

If

The address is for Vijayawada

Then display the message "Vijayawada bus is leaving the out gate"

Enable the APB module

Else if

The address is for Khammam

Then Display the message "Khammam Bus is leaving the out gate"

Enable the APB module

Else if

The Address is for Kothagudem

Then Display the message "Kothagudem bus is leaving the out gate"
Enable the APB module

Else

Decrement the loop 3 iteration count by 1

Open the out gate

Go to loop 1

\section{RESULTS AND DISCUSSION}

The experiments were conducted by keeping the RF ID tags to the Tested Bus and the RFID reader is positioned at the entrance gate of the bus stand. The output signals of the RFID reader is communicated to the Arduino micro controller serially using RS 232 serial communication protocol. PD'0' pin of the Microcontroller is used to receive the signals from the RFID reader. The received signals will be analyzed to enable the output devices. L293D H-Bridge circuit is used to drive the motor assembly positioned at the input and output gate of the bus stand. The In gate will be opened only when an authorized address is detected at the gate level. The out gate is normally in closed state. The On state of the IR sensors positioned at the parking places cause to enable the display and announcement systems. Fig.5 and Fig.6 Represents the developed working model of the yerragunta bus stand. The controller represented in fig.6 is used to drive the gate to be open when an authorized bus detected by the RFID reader. The gate will be closed once the bus leaves the gate. Fig.11 represents the control room to regulate the position and movements of the bus. Fig.9 and Fig.10 represents the display status of the Vijayawada bus leaving the platform and Khammam Bus at the platform with audio announcement. After repeated testing of the developed model the applied EM-18 RFID reader responded favorably to the RFID tag housed with the bus entering into the stand. With the use of IR detectors the response time is improved with no delay while bus is entering towards the platform.

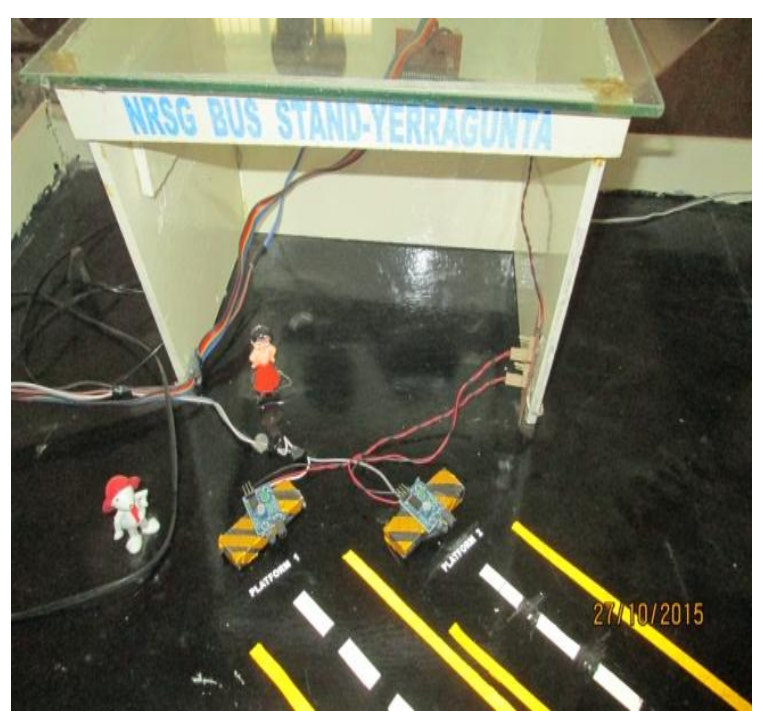

Fig.5 Yerragunta Bus Stand view 


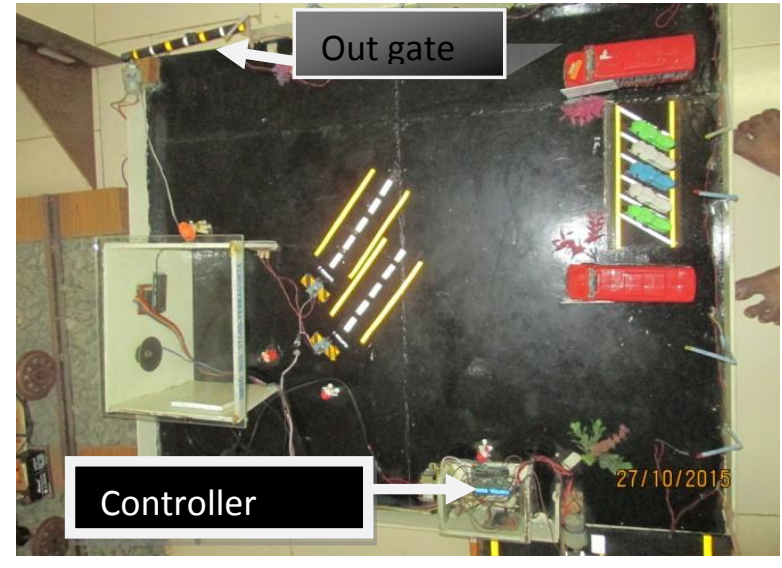

Fig.6 Developed working model

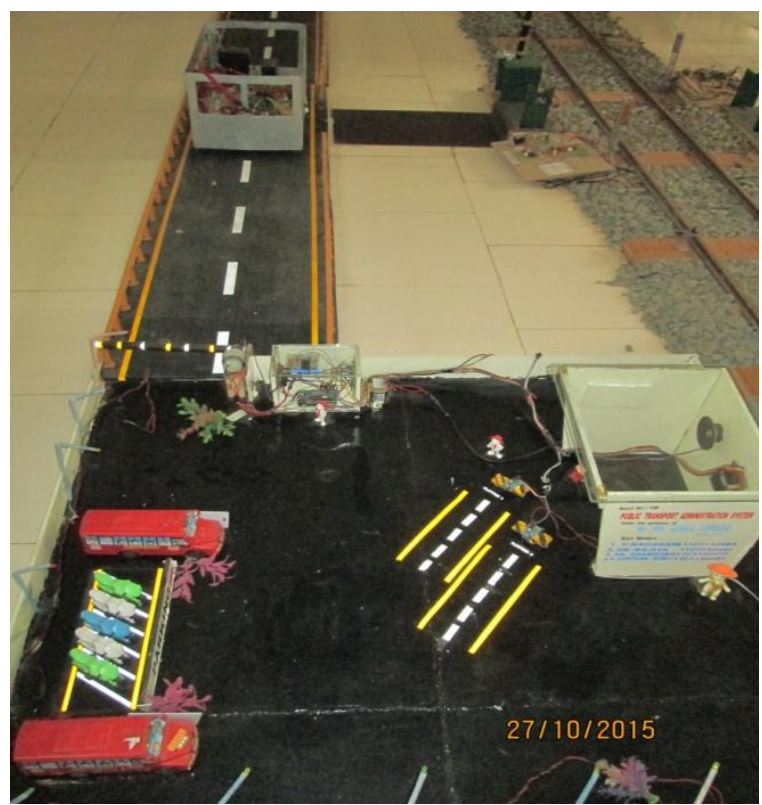

Fig.7 Bus Entering into the bus stand

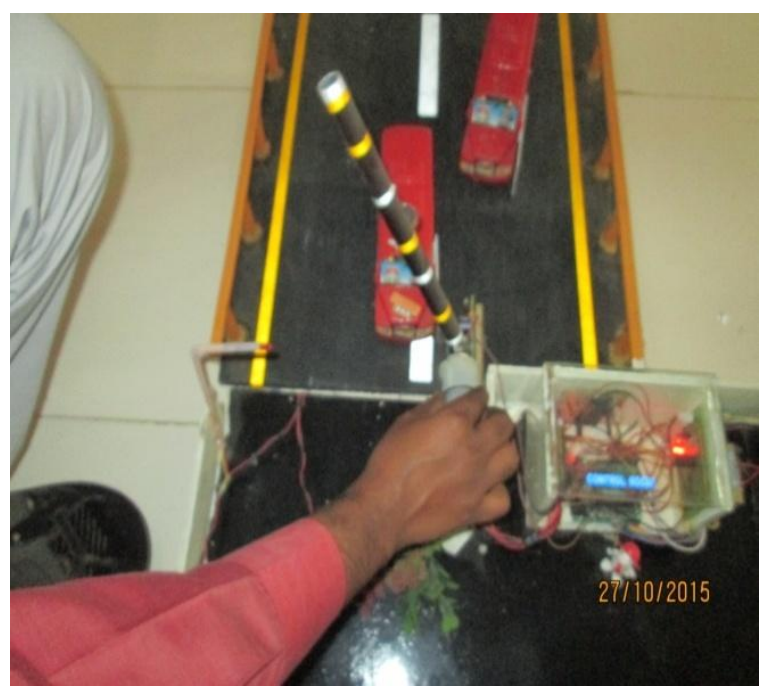

Fig.8 Bus detected, gate open state

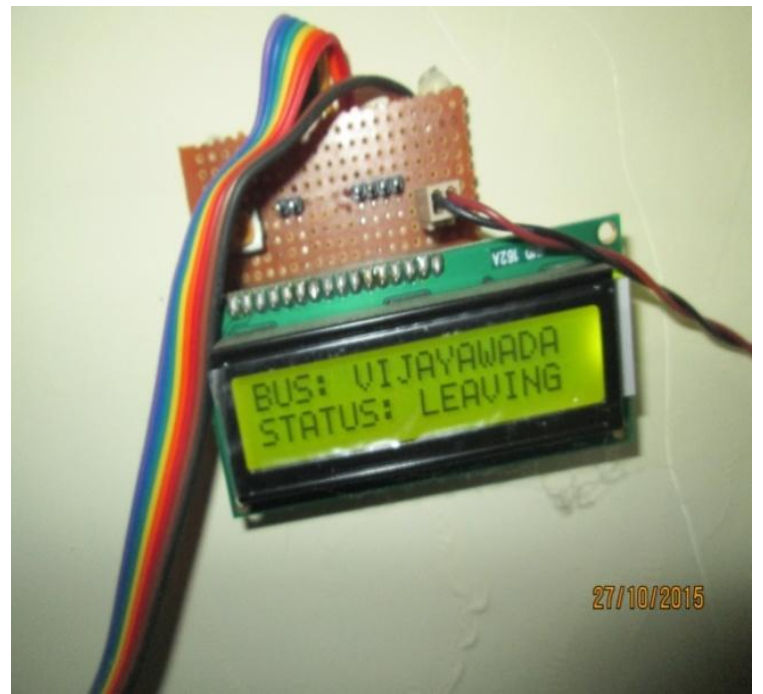

Fig.9 Bus leaving status

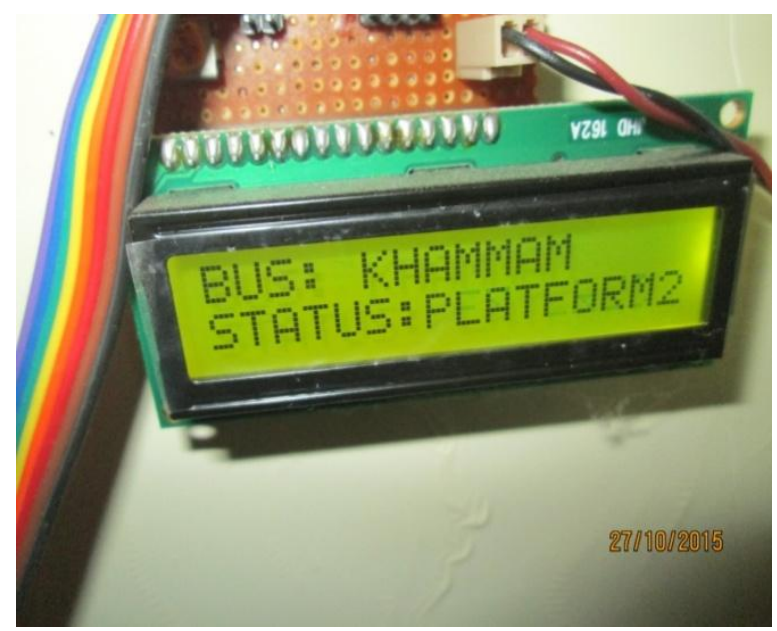

Fig.10 Bus at platform

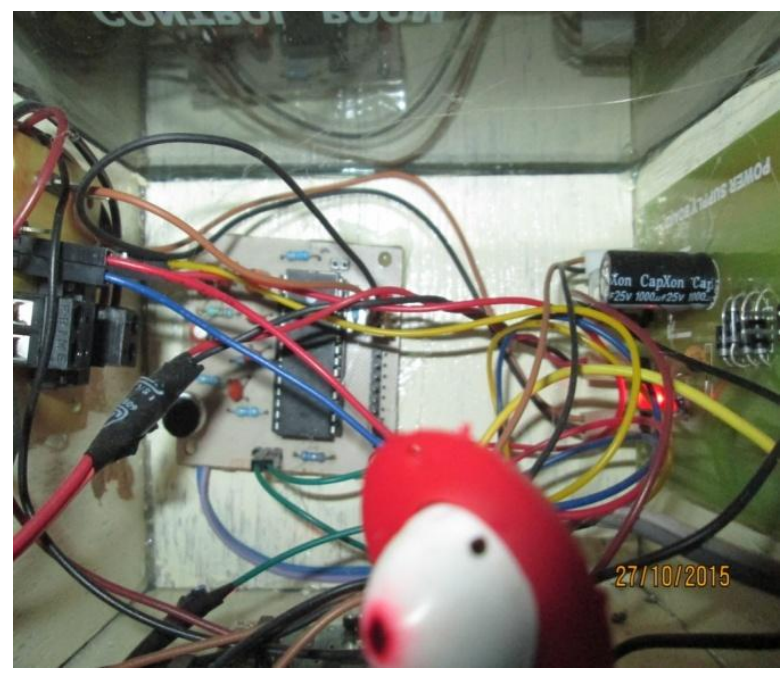

Fig.11 Control room

\section{CONCLUSION}

The proposed methodology was implemented in our in house research department. Majority of the researchers focused on the prediction mechanism of the bus arrival and its current location. This work focused on bus station management system. The status of the bus at the platform may curtail the 
waiting time of the passengers. Arduino micro controller reached the desired expectations of the work. The regulatory mechanism at the in and out gate may enable the security system of the passengers by restricting the unauthorized entry.

In future this work may be further extended with Internet of things by incorporating the web based applications. So the travel passengers can observe the state of the bus at their desired location points.

\section{ACKNOWLEDGEMENT}

Authors would like to express their sincere thanks to the management and principal of Sai Spurthi Institute of Technology for providing the fund and necessary infrastructure. And also thank to Mr. Prassanna Kumar in charge of Radio frequency department Sak informatics.

\section{REFERENCES}

[1] Mrs.Swati Chandurkar, Sneha Mugade, Sanjana Sinha, Megharani Misal, Pooja Borekar, "Implementation of Real Time Bus Monitoring and Passenger Information System", International Journal of Scientific and Research Publications, Vol 3( 5): pages 1-5, May 2013

[2] A. Menon1, R. Sinha, D. Ediga, Prof. Subba Iyer, "implementation of internet of things in bus transport system of Singapore", Asian Journal of Engineering Research, Vol I( IV):8-17, July-Sept.2013.

[3] Aparna A. Surve, Rutuja P. Nahar, Gauri K. Somavanshi, Kranti Dive," Enhancing The Functionality Of Bus Monitoring And Tracking System", international journal of technology enhancements and emerging engineering research, vol 3(04), 93-97, 2015.

[4] Sunil Praneel Narayan, Mansour H. Assaf, Shalvindra Krishneel Prasad, "Wireless Sensor Enabled Public Transportation System", International journal of Communications, Network and System Sciences, Vol: Vol 8, pages 187-196, 2015.

[5] Gunjal Sunil N. , Joshi Ajinkya V. , Gosavi Swapnil C. , Kshirsagar Vyanktesh B.," Dynamic Bus Timetable Using GPS”, International Journal of Advanced Research in Computer Engineering \& Technology (IJARCET) Vol 3 ( 3): pages 775-778, March 2014.
[6] Karan Punjabi, Pooja Bolaj, Pratibha Mantur, Sneha Wali, "Bus Locator via SMS Using Android Application", International Journal of Computer Science and Information Technologies, Vol. 5 (2) , 2014, pages, 1603-1606.

[7] Swapnil Bhosale, Abhishek Aru,Tushar Jashav,Vikas Kalokhe,Santosh Sambare, "RFID Based Bus Tracking System" , International Journal of Research in Computer and Communication Technology, Vol. 3(2 ):208-212, February- 2014.

[8] Komal Agarwal, Kimaya Dhaigude, Priyanka Kataria, Dipti Parakh," Design of Embedded Device for Public Transportation Management System”, International Journal of Advance Research in Computer Science and Management Studies, Volume 2, Issue 2,pages 297-303, February 2014.

[9] Rohan Kale," Real Time Passenger Information System”, International Journal of Advanced Research in Computer Science \& Technology, Vol. 2, Issue 3: 153-155,July Sept. 2014.

\section{AUTHOR'S BIOGRAPHY}

K.Vidyasagar: Received B. Tech degree in Instrument Technology from Andhra University College of Engineering Visakhapatnam, M.E from P.S.G.Tech Coimbator. He is now a research scholar under the guidance of Dr. A. Bhujangarao, Andhra University. His current research interests include image processing in biomedical instrumentation and related embedded systems.

Abdul Farooq basha received B. Tech in Electronics and Communication Engineering from JNTU Hyderabad and M.Tech in VLSI\&SD from JNTU Kakinada. His research interest is in Micro controllers and embedded system applications.

K. Suresh received B. Tech degree in Electronics and Communication Engineering from JNTU Hyderabad and M.Tech in Electronics and Communication Engineering from JNTU Hyderabad. His research interest is in Micro controllers and embedded system applications. 